\title{
Neonatal cholestasis due to citrin deficiency: diagnostic pitfalls
}

\author{
Patryk Lipiński1四, Dorota Jurkiewicz², Elżbieta Ciara², Rafał Płoski³, Sabina Więcek ${ }^{4}$ \\ Anna Bogdańska ${ }^{5}$, Teresa Stradomska ${ }^{5}$, Piotr Socha ${ }^{6}$, Dariusz Rokicki ${ }^{1}$, Anna Tylki-Szymańska ${ }^{1}$ \\ and Irena Jankowska6
}

1Department of Pediatrics, Nutrition and Metabolic Diseases, The Children's Memorial Health Institute, Warsaw, Poland; ${ }^{2}$ Department of Medical Genetics, The Children's Memorial Health Institute, Warsaw, Poland; 3Department of Medical Genetics, Medical University of Warsaw, Warsaw, Poland; “Department of Pediatrics, School of Medicine in Katowice, Medical University of Silesia, Katowice, Poland; ${ }^{5}$ Department of Biochemistry, Radioimmunology and Experimental Medicine, The Children's Memorial Health Institute, Warsaw, Poland; ${ }^{\circ}$ Department of Gastroenterology, Hepatology, Feeding Disorders and Pediatrics, The Children's Memorial Health Institute, Warsaw, Poland

\begin{abstract}
Citrin deficiency can manifest in newborns or infants as neonatal intrahepatic cholestasis caused by citrin deficiency (NICCD). The paper presents a case of Polish NICCD patient presenting with low birth weight, failure to thrive, prolonged cholestatic jaundice with coagulopathy and hypoalbuminemia with normal results of MS/ MS newborn screening but with high blood citrulline level observed at 3 months of age. Unreported findings included $\mathrm{N}$-hypoglycosylation and increased serum verylong-chain fatty acids (VLCFA), probably secondary to liver impairment. Final diagnosis was established based on whole-exome sequencing (WES) analysis.
\end{abstract}

Key words: citrin deficiency, neonatal intrahepatic cholestasis caused by citrin deficiency, citrullinemia, newborn screening, verylong-chain fatty acids, protein N-hypoglycosylation

Received: 09 March, 2020; revised: 23 April, 2020; accepted: 13 May, 2020; available on-line: 21 May, 2020

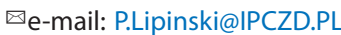

Funding sources: The study was funded by The Children's Memorial Health Institute intramural grant M28/17.

Abbreviations: a1-AT, Alpha-1-antitrypsin; AFP, alpha-fetoprotein; ALT, alanine aminotransferase; AST, apartate aminotransferase; CTLN2, citrullinemia type II; FTTDCD, failure to thrive and dyslipidemia due to citrin deficiency; GC/MS, urinary gas chromatography-mass spectrometry; GGTP, gamma-glutamyl transferase; IEF, isoelectric focusing; INR, international normalized ratio; LTx, liver transplantation; MS/MS, tandem mass spectrometry analysis; NGS, next-generation sequencing; NICCD, neonatal intrahepatic cholestasis due to citrin deficiency; UDCA, ursodeoxycholic acid; VLCFA, very-long-chain fatty acids; WES, whole-exome sequencing

\section{BACKGROUND}

Citrin deficiency is an autosomal recessive urea cycle defect caused by biallelic pathogenic variants of the SLC25A13 gene, that could result in three various age-dependent phenotypes: neonatal intrahepatic cholestasis (NICCD, OMIM 605814), failure to thrive and dyslipidemia (FTTDCD) in older children, and adult-onset type II citrullinemia (CTLN2, OMIM 603471), respectively. NICCD typically manifests with cholestatic jaundice, failure to thrive, hypoproteinemia, coagulopathy, and multiple aminoacidemia including citrullinemia. In almost all patients the condition is self-limiting between 6 and 12 months of age. Some patients diagnosed with NICCD could develop FT'TDCD and/or CTLN2 later in life, thus an early diagnosis remains crucial (Okano et al., 2019; He et al., 2019; Numakura et al., 2019; Chong et al., 2018; Tamamori et al., 2002; Ohura et al., 2007; Tazawa et al., 2004; Tang et al., 2019; Shigeta et al., 2010; Kakiuchi et al., 2020; Kobayashi et al., 1999; Tazawa et al., 2001).

We describe the clinical, biochemical, and molecular features of a Polish patient diagnosed with NICCD, and provide an overview of diagnostic pitfalls.

\section{CASE REPORT}

The patient was the third child of nonconsanguineous Polish parents born from an uneventful pregnancy at 38 weeks of gestation with a birth mass of $2580 \mathrm{~g}$ (birth mass of two previous children was above $3000 \mathrm{~g}$ ). At the age of 5 weeks, he was referred to the local hospital due to prolonged jaundice and poor weight gain (body mass $3020 \mathrm{~g},<3$ rd centile). Cholestasis accompanied by slightly elevated serum transaminases, hypoalbuminemia and coagulopathy was diagnosed (Table 1). No history of hypo-/acholic stools was observed. Normal liver and spleen volume as well as the presence of gallbladder in abdominal ultrasound were observed. Infectious causes of cholestasis, including $\mathrm{HBV}, \mathrm{HCV}, \mathrm{CMV}$, EBV, HIV, and Toxoplasma gondii infections, were excluded serologically. Alpha-1-antitrypsin ( $\alpha 1-A T)$ deficiency (based on normal serum $\alpha 1-\mathrm{AT}$ level), cystic fibrosis (based on normal serum immunoreactive trypsinogen level as a part of newborn screening programme), galactosemia (based on active galactose-1-phosphate uridylyltransferase) were excluded as well. Serum ammonia was not tested at this consultation. The improvement of cholestatic features was observed on ursodeoxycholic acid (UDCA) as well as fat-soluble vitamins treatment.

Due to raising parameters of cholestasis, noted at the age of 8 weeks, the child was transferred to our hospital. Patient's weight on admission was $3800 \mathrm{~g}$ (still $<3$ rd centile). The psychomotor development was normal. Results of laboratory analyses are shown in Table 1. Notably, several measurements revealed the serum ammonia to be mildly elevated. Serum alpha-fetoprotein (AFP) was noted elevated as well. Urinary gas chromatography-mass spectrometry (GC/MS) analysis revealed large quantities of 4-hydroxyphenylacetic acid and 4-hydroxyphenylpyruvate acid; succinylaceton was not detected, which allowed to exclude tyrosinemia. Protein $\mathrm{N}$-hypoglycosylation in the form of increased a-, mono-, as well as di-sialotransferrin, was also detected. Tandem mass spectrometry analysis (MS/MS) of serum amino acids (AA) revealed high levels of citrulline (430 umol/l, reference range $1-55)$, threonine (475 umol/l, reference 
Table 1. Biochemical features of the reported NICCD patient (n.a. - not analyzed).

\begin{tabular}{|c|c|c|c|c|c|}
\hline \multirow{2}{*}{ Parameter and reference values } & \multicolumn{5}{|c|}{ Age } \\
\hline & 5 weeks & 2 months & Admission to our hospital (9 weeks) & 6 months & 9 months \\
\hline Platelets [150-450 K/ul] & 400 & 488 & 445 & 458 & 295 \\
\hline Total serum bilirubin $[<1.00 \mathrm{mg} / \mathrm{dl}]$ & 12.2 & 10.0 & 9.6 & 0.56 & 0.24 \\
\hline Direct serum bilirubin $[<0.2 \mathrm{mg} / \mathrm{dl}]$ & 2.7 & 4.0 & 4.5 & 0.45 & 0.12 \\
\hline AST $[<60 \mathrm{U} / \mathrm{I}]$ & 64 & 70 & 101 & 121 & 94 \\
\hline $\mathrm{ALT}[<60 \mathrm{U} / \mathrm{I}]$ & 26 & 28 & 30 & 71 & 58 \\
\hline GGTP $[<200 \mathrm{U} / \mathrm{l}]$ & 135 & 115 & 147 & 108 & 21 \\
\hline INR $[0.9-1.3]$ & 2.1 & 1.62 & 1.99 & 1.18 & 1.09 \\
\hline Albumin $[3.8-5.4 \mathrm{~g} / \mathrm{dl}]$ & 2.4 & 2.2 & 2.5 & 3.29 & 3.84 \\
\hline Serum bile acids $[<10.0 \mathrm{umol} / \mathrm{l}]$ & n.a. & 294 & 313.6 & $<10.0$ & n.a. \\
\hline Serum ammonia $[27-102 \mathrm{ug} / \mathrm{dl}]$ & n.a. & n.a. & $180-220$ & 165 & 60 \\
\hline Serum lactate $[4.5-19.8 \mathrm{mg} / \mathrm{dl}]$ & n.a. & n.a. & 24.7 & n.a. & n.a. \\
\hline AFP $[<5.0 \mathrm{IU} / \mathrm{ml}]$ & n.a. & n.a. & 82500 & 2340 & n.a. \\
\hline
\end{tabular}

range $73-160)$, tyrosine (283 umol/1, reference range 2986), lysine (407 umol/1, reference range 68-266), arginine (242 umol/1, reference range 6-187). Increased results of serum very-long-chain fatty acids (VLCFA), C24:0/ C22:0 - 1.178, $\mathrm{N}<0.96$; C26:0/C22:0 - 0.03, $\mathrm{N}<0.02$, were also noted.

Diagnosis of chronic cholestatic liver disease of an unknown etiology was established. Treatment, including UDCA as well as fat-soluble vitamins was continued. Due to presence of liver failure, the child was qualified to liver transplantation (LTx) procedure, and thus decision about molecular analysis (whole-exome sequencing, WES) was made. Results of all biochemical abnormalities were missed due to ongoing WES analysis.

During follow-up, at 6 months of age, the remission of cholestasis occured (Table 1). Serum AFP decreased

Table 2. Literature overview of the presented patient's features.

\begin{tabular}{|c|c|}
\hline \multicolumn{2}{|l|}{ Reported features } \\
\hline Feature & Presented case \\
\hline Low birth weight (often around $2500 \mathrm{~g}$ ) & + \\
\hline Failure to thrive & + \\
\hline Prolonged jaundice & + \\
\hline Acholic stools & - \\
\hline Intrahepatic cholestasis & + \\
\hline Hypoglycemia & - \\
\hline Hypoproteinemia & + \\
\hline Coagulopathy & + \\
\hline Elevated GGT & - \\
\hline Elevated serum transaminases & + \\
\hline Multiple aminoacydemias, including citrullinemia & + \\
\hline Mild increase of serum ammonia level & + \\
\hline Remission of cholestasis (often between 6 and 12 months of age) & + \\
\hline \multicolumn{2}{|l|}{ Not reported features } \\
\hline & Protein N-hypoglycosylation \\
\hline & Increased serum VLCFA \\
\hline
\end{tabular}

while serum transaminases as well as ammonia level persisted as mildly elevated; oral lactulose was implemented. Normal serum ammonia was noted at the age of 9 months. In the whole-exome sequencing (WES) study, the patient was found to be homozygous for the novel splice site variant c.1453-2A>T in the SLC25A13 gene. The child was disqualified from LTx. Dietary treatment based on lipid and protein-rich low-carbohydrate was introduced.

\section{DISCUSSION}

Retrospectively, our patient showed almost all clinical and biochemical features of NICCD as summarized in Table 2. Unreported findings included protein N-hypoglycosylation and increased serum VLCFA. The main di- 
agnostic pitfall was that results of all biochemical abnormalities, especially high citrullinemia serum level, were missed due to ongoing WES analysis.

The diagnostic approach of neonatal/infantile cholestasis is traditionally based on clinical, biochemical, imaging and histopathological findings (Sticova et al., 2018; Fawaz et al., 2017). Diagnosis of citrin deficiency is usually made on clinical and biochemical features including low birth weight, failure to thrive, early neonatal cholestasis with hypoalbuminemia, coagulopathy and elevated serum transaminases (Okano et al., 2019; He et al., 2019; Numakura et al., 2019; Chong et al., 2018; Tamamori et al., 2002; Ohura et al., 2007; Tazawa et al., 2004). Multiple aminoacidemia, including citrullinemia, are observed in majority of NICCD cases. In the presented case, amino acid and acylcarnitine profiles were normal in dried blood spots of newborn screening program. A relatively high blood citrulline level, observed at 3 months of patient's age, was characteristic for NIC$\mathrm{CD}$ but it was missed due to ongoing WES analysis. The limited sensitivity of NICCD newborn screening may be related to an early blood sampling time (Tang et al., 2019).

A mild increase in the serum ammonia level was observed in our patient as well as in some reported NICCD patients. This is usually asymptomatic and the improvement on lactulose could be also misleading. Moreover, in the presented case, the serum ammonia level was analyzed for the first time at the age of 2 months. This is a cheap laboratory analysis and should be available at every neonatal unit. Monitoring of serum ammonia level reflects a valuable marker of liver metabolic disorders, therefore it should be carried out frequently.

However, there are some non-specific probably secondary biochemical features which were observed in our patient.

Increased serum VLCFA accumulation found in our patient was probably caused by a decreased peroxisomal activity in the liver tissue. It is not an unique finding; the ratio of $\mathrm{C} 24: 0 / \mathrm{C} 22: 0$ as well as $\mathrm{C} 26: 0 / \mathrm{C} 22: 0$ had been reported as increased in patients with liver insufficiency (Stradomska et al., 2013).

The abnormal serum isoelectric focusing (IEF) profile, indicative for protein N-hypoglycosylation, was also found. Since its introduction in 1984, serum transferrin IEF is still the method of choice for the diagnosis of $\mathrm{N}$-glycosylation disorders with sialic acid deficiency (Jaeken et al., 1984). Some patients, including those with classic galactosemia (galactose-1-phosphate uridyltransferase deficiency), fructosemia (fructose 1-phosphate aldolase deficiency), severe liver impairment (personal observations), have secondarily an abnormal serum transferrin isoform profile. In our patient, this phenomenon was probably secondary to liver impairment in the course of citrin deficiency.

The final diagnosis of NICCD in our patient was established based on molecular analysis. The identificable causes of cholestasis have grown recently due to application of next-generation sequencing (NGS) technology (Sticova et al., 2018; Fawaz et al., 2017). Since the first reports of NICCD in Asian children, citrin deficency became now recognizable as a panethnic disorder.

NICCD is usually a self-limiting disease with remission of cholestasis seen between 6 and 12 months of age (Okano et al., 2019; He et al., 2019; Numakura et al., 2019; Chong et al., 2018; Tamamori et al., 2002; Ohura et al., 2007; Tazawa et al., 2004). The biochemical improvement seen on UDCA therapy could be also misleading for the definite diagnosis. However, there are few reports of patients who develop severe liver failure requiring liver transplantation (LTx) or died before LTx (Shigeta et al., 2010).

\section{CONCLUSIONS}

The paper presents a case of Polish NICCD patient presenting with low birth weight, failure to thrive, prolonged cholestatic jaundice with coagulopathy and hypoalbuminemia with normal results of $\mathrm{MS} / \mathrm{MS}$ newborn screening but with high blood citrulline level observed at 3 months of age. Unreported findings included protein N-hypoglycosylation and increased serum very-longchain fatty acids (VLCFA), probably secondary to liver impairment. The main diagnostic pitfall was that results of all biochemical abnormalities, especially high serum citrulline level, were missed due to ongoing WES analysis.

\section{Conflict of interest}

All authors declare no conflict of interest.

\section{REFERENCES:}

Chong SC, Lo P, Chow CW, Yuen L, Chu WCW, Leung TY, Hui J, Scaglia F (2018) Molecular and clinical characterization of citrin deficiency in a cohort of Chinese patients in Hong Kong. Mol Genet Metab Rep 17: 3-8. https://doi.org/10.1016/i.ymgmr.2018.08.002

Fawaz R, Baumann U, Ekong U, Fischler B, Hadzic N, Mack CL, McLin VA, Molleston JP, Neimark E, Ng VL, Karpen SJ (2017) Guideline for the evaluation of cholestatic jaundice in infants: joint recommendations of the North American Society for Pediatric Gastroenterology, Hepatology, and Nutrition and the European Society for Pediatric Gastroenterology, Hepatology, and Nutrition. J Pediatr Gastroenterol Nutr 64: 154-168. https://doi.org/10.1097/ MPG.0000000000001334

He J, Zhang J, Li X, Wang H, Feng C, Fang F, Shu S (2019) A case report: can citrin deficiency lead to hepatocellular carcinoma in children? Front Pediatr 7: 371. https://doi.org/10.3389/fped.2019.00371

Jaeken J, Eijk HG, Heul L, Corbeel L, Eeckels R, Eggermont E (1984). Sialic acid-deficient serum and cerebrospinal fluid transferrin in a newly recognized genetic syndrome. Clin Chim Acta 144: 245-247. https://doi.org/10.1016/0009-8981(84)90059-7

Kakiuchi T, Nakayama A, Akiyama T, Martsuo M (2020) Chronic pancreatitis and pancreatic pseudocyst with adult-onset type II citrullinemia. Clin J Gastroenterol 13: 97-101. https://doi.org/10.1007/ s12328-019-01011-8

Kobayashi K, Sinasac DS, Iijima M, Boright AP, Begum L, Lee JR, Yasuda T, Ikeda S, Hirano R, Terazono H (1999) The gene mutated in adult-onset type II citrullinaemia encodes a putative mitochondrial carrier protein. Nat Genet 22: 159-163. https://doi. org/10.1038/9667

Numakura C, Tamiya G, Ueki M, Okada T, Maisawa SI, Kojima-Ishii K, Murakami J, Horikawa R, Tokuhara D, Ito K, Adachi M, Abiko T, Mitsui T, Hayasaka K (2019) Growth impairment in individuals with citrin deficiency. I Inherit Metab Dis 42: 501-508. https://doi. org/10.1002/jimd.12051

Ohura T, Kobayashi K, Tazawa Y, Abukawa D, Sakamoto O, Tsuchiya S, Saheki T (2007) Clinical pictures of 75 patients with neonatal intrahepatic cholestasis caused by citrin deficiency (NICCD) (2007). J Inherit Metab Dis 30: 139-144. https://doi.org/10.1007/s10545007-0506-1

Okano Y, Ohura T, Sakamoto O, Inui A (2019) Current treatment for citrin deficiency during NICCD and adaptation/compensation stages: Strategy to prevent CTLN2. Mol Genet Metab 127: 175-183. https://doi.org/10.1016/j.ymgme.2019.06.004

Shigeta T, Kasahara M, Kimura T, Fukuda A, Sasaki K, Arai K, Nakagawa A, Nakagawa S, Kobayashi K, Soneda S, Kitagawa H (2010) Liver transplantation for an infant with neonatal intrahepatic cholestasis caused by citrin deficiency using heterozygote living donor. Pediatr Transplant 14: E86-E88. https://doi.org/10.1111/j.13993046.2009.01172.x

Sticova E, Jirsa M, Pawłowska J (2018) New insights in genetic cholestasis: from molecular mechanisms to clinical implications. Can J Gastroenterol Hepatol 2018: 2313675. https://doi. org/10.1155/2018/2313675

Stradomska TJ, Bachański M, Pawłowska J, Syczewska M, Stolarczyk A, Tylki-Szymańska A (2013) The impact of a ketogenic diet and 
liver dysfunction on serum very long-chain fatty acids levels. Lipids 48: 405-409. https://doi.org/10.1007/s11745-013-3761-y

Tamamori A, Okano Y, Ozaki H, Fujimoto A, Kajiwara M, Fukuda K, Kobayashi K, Saheki T, Tagami Y, Yamano T (2002) Neonatal intrahepatic cholestasis caused by citrin deficiency: severe hepatic dysfunction in an infant requiring liver transplantation. Eur J Pediatr 161: 609-13. https://doi.org/10.1007/s00431-002-1045-2

Tang CF, Liu SC, Feng Y, Mei HF, Liu HP, Feng JW, Ye LX, Wang GQ, Liu L, Huang YL (2019) Newborn screening program and blood amino acid profiling in early neonates with citrin deficiency. Zhonghua Er Ke Za Zhi 57: 797-801. https://doi.org/10.3760/cma.j.i ssn.0578-1310.2019.10.014
Tazawa Y, Kobayashi K, Abukawa D, Nagata I, Maisawa S, Sumazaki R, Iizuka T, Hosoda Y, Okamoto M, Murakami J (2004) Clinical heterogeneity of neonatal intrahepatic cholestasis caused by citrin deficiency: case reports from 16 patients. Mol Genet Metab 83: 213219. https://doi.org/10.1016/j.ymgme.2004.06.018

Tazawa Y, Kobayashi K, Ohura T, Abukawa D, Nishinomiya F, Hosoda Y, Yamashita M, Nagata I, Kono Y, Yasuda T (2001) Infantile cholestatic jaundice associated with adult-onset type II citrullinemia. J Pediatr 138: 735-740. https://doi.org/10.1067/mpd.2001.113264 